\title{
Perception of Empowerment among International Students at the University Putra Malaysia
}

\author{
Odigbo Ikechukwu Aloysius ${ }^{1}$ \\ ${ }^{1}$ Faculty of Educational Studies Universiti Putra Malaysia, Malaysia \\ Correspondence: Odigbo Ikechukwu Aloysius, Department of Human Resources Development, Faculty of \\ Educational Studies, Universiti Putra Malaysia, UPM, 43400 Serdang, Selangor, Malaysia. Tel: 60-16-266-5250. \\ E-mail: ikon84@yahoo.com
}

Received: August 19, 2013

Accepted: October 18, 2013 Online Published: November 15, 2013

doi:10.5539/ijbm.v8n23p93

URL: http://dx.doi.org/10.5539/ijbm.v8n23p93

\begin{abstract}
Empowerment means enhancement of student's autonomy for decision making. Reports have shown that students who are empowered perform better, and have better relationship with the staff. Therefore this study was carried out to explore the experience of student's empowerment at the Universiti Putra Malaysia (UPM) Malaysia. Informed by a phenomenological qualitative research design, analysis of various sources of primary data was carried out using semi-structured interviews with international and local students to understand their opinions and perceptions about empowerment. Results obtained were analyzed, transcribed and discussed about their perception of empowerment and the effect on performance. The findings showed a sense of dis-empowerment among the informants was due to lack of motivation and problems associated with integration between the students and the staff. Student's reported that they can be empowered by allowing them more freedom in their studies. However, they recommend that management should assist in sensitizing local student's to feel free to socialize with international students for improved performance.
\end{abstract}

Keywords: empowerment, phenomenology, autonomy, performance and integration

\section{Introduction}

Empowerment is derived from diverse perspectives which includes education, industrial and organizational psychology, service perspectives etc. From a service perspective, empowerment gives employees the authority to make decisions about customer service. While in industrial and organizational psychology and management, empowerment is the enhancement of the autonomy of employees in their work or increased involvement that results in increased decision making more generally within the wider agenda and interests of the organization (Wall et al., 2004). Empowerment is defines as "the process of developing power, gaining power, seizing or taking power, or enabling power or facilitating" (Parson 1991). It is one areas of directly or indirectly providing for the relegated people with organised several activities speaking against such vices, and with a promise to stopping such an occurrence in the future. This is the only area where those affected can be reconstituted and reinstated mentally, socially and psychologically. According to Nystanga and Dann (2002) empowerment both a "process and an outcome comprising persons or groups' ability to pull from within them the power to control or influence significant events in their lives." Moreover, empowerment process is non-linear, dynamic and fluctuates in response to personal relationships and experiences with others (Camp 2003) Reports have shown that students who are empowered perform better than those that are marginalized as well as having better relationship with staff members and other students. They are more active in community participation. In the University Putra Malaysia (UPM) for example international students are unable to take part in some curricular and extra-curricular activities. This has resulted to complains, insufficient spread of information sharing, inadequate team accountability, interference in communication among lecturers and students. Students being afraid of airing their problems or asked questions about issues that affected them to lecturers and other staff, thus hindering their academic works. They are afraid of asking questions to better understand the program for good results. This must be addressed through psychological empowerment so as to improve development within the university. Notwithstanding the many advantages of empowerment among student's limited researches in Malaysia and at UPM that looks at international students experiences with empowerment. This study looks at the empowerment perceptions among international students in the educational studies and performance in the study place. It is 
known that empowerment is essential for students to thrive, yet we do not know how the students perceive their experiences in terms of being empowered. Therefore this study was chosen to address the gap.

Based on the problem identified above, the current study addressed the following research questions.

- How do international students experience empowerment at the Universiti Putra Malaysia?

- How does their sense of empowerment influence their performance as students?

\subsection{Significance of the Study}

Students'with highly motivational empowerment, determines how efficient academics assessment is going to be.The study seeks to understand the need for student's characteristics and empowerment and academic performance improvement at UPM. This is with a view to harness student's perception of empowerment and brings about a solution for improved information sharing, and trust for improved academic performance at the faculty; as well as foster integration among teachers, other staff, international students and the local students.

\subsection{Objectives of the Study}

- To explore the experiences of marginalization and or disempowerment of students at the University Putra Malaysia.

- To determine the roles of lecturers, management and other students on the empowerment strategies at University Putra Malaysia.

- To determine the students perceptions about, empowerment and its relationship to performance at University Putra Malaysia.

\section{Literature Review}

\subsection{Empowerment Concept}

The concept of empowerment is thought important because of organizational and personal gains (Han et al., 2009). According to Moye and Henkin (2005), Moye and Henkin (2006), empowerment concept has aroused interest among practitioners and organizational theorists. It has been adopted by both the practitioners and researchers as a means of improving employments' work experience (Liden and et al., 2000). Scholars may adopt psychological empowerment as a way of motivation to realize their performance level in research and teaching. Psychological empowerment is comprised of interaction, interpersonal and behavioural empowerment. Many effects of researches have cantered on psychological empowerment in business education. The mechanism (motivational and cognitive) of psychological empowerment shows management impact on performance study. The concept of empowerment is borne from providing skills to students, authority resources, and motivation as well as holding them accountable and responsible for the result of their actions, will contribute to their competence and satisfaction.

\subsection{Leadership and Empowerment}

Empowerment is encouraged by leadership, an empowered organization is one in which the people are supervised more by managers compared to the traditional stages and assign more decision makings to their subordinates (Malone, 1997). The most important factors that contribute to empowerment, engagement and satisfaction of employees are based on their relationship with the leader (Eisenberger et al., 2002; Rhoades et al., 2001). Bell and Kozlowski (2002) have stressed the role of leadership for the effectiveness of virtual teams. Moreover, Bell and Kozlowski (2002) expect a leader to form more explicit procedures and structures. Employees empowerment accepts additional responsibilities and become more autonomous can be one of the best ways for organizational effectiveness, improvement and satisfy customers. Moreover, Sparkset al., (1997) have reported that when more employees are fully empowered, lesser service failures may occur. A major characteristic of the high-tech industry, where complexity and uncertainty are high comparatively, is the large proportion of top level professionals it employs working together across firm levels. These individuals working together hold advanced degrees in different professional areas. Empowering this kind of team may lead to improvement in the coordination and communication processes, as members of the team may be more eager to commit themselves to tasks that they have agreed upon. Parolia et al. (2007) have argued that empowerment enhances positively information system (IS) performance project

\subsection{Motivation}

Motivation involved mainly pre-decisional state of an individual, with that which influences the action of a decision. While volition involves mainly post-decisional state i.e. with that which influences a decision once it is made to follow through. Motivation is comprised of established opinion for example external and internal goal 
orientation, self-efficacy, self-esteem as well as diverse interpretation attributes. Although volition is a term that is less known, it tries to describe perceptions for example self-regulation, persistence, self-evaluation and control of motivational empowerment also lead to high or low performance.

\subsection{Student Empowerment for Civility Promotion}

Self-direction, psychic comfort, motivation and solving problems are channels of encouraging empowerment in education and are the basic elements for students' empowerment. Academic empowerment is comprised of the student's capacity to build the confidence, ability, and motivation to academic success (McQuillan 2005). Clark (2008) has shown that incivility within the student faculty relationship is mutual and naturally interactional and occurs as a reciprocal exchange. The mutual nature of the student and faculty interactions have been described by Clark (2008), with illustrations on the changing interface between both groups that may lead to incivility or conflict or in a culture of respect and civility. Therefore, it is noteworthy that when the faculty and students jointly work for conflict resolution, and when a party communicates and strongly embarks on meaningful dialogue, the civility potential is improved while a safer and more civil learning is formed. Efficiency in communication and engagement are the major areas that brings into existence educational civility culture and integration, but if there were absence of integration, It's will lead to unsatisfactory attitude among international students to cope with teaching method and learning processes.

\subsection{Psychic Comfort}

Psychic comfort means the ability to protect self against damaging impulses as well as protect oneself from harm (Bloom 1998). For instance joint creation of classroom norms encourages personal and group behavioural awareness which assists in or hinder civility. Role modelling of the faculty as well play significant roles in civil classroom creation. When civility is practices and presents an acceptable atmosphere, students regularly responds in kind. Dressing professionally is important and starting and ending classes on time, and setting a respectful and inclusive tone.

Adopting a syllabus that is user friendly and clear as well as the teaching philosophy of Professor, the activities of societal discourse and student's detailed ways to be a success in the course assists in encouraging a safe environment of learning (Clark 2009). Alternatively, ensuring students participation in making decision and governance in the institution and provision of open for a dialogue on civility and identifying acceptable conduct codes are another ways of creating a civil classroom environment (Clark 2008).

\subsection{Typical Empowerment Model}

According to the view of Turner (1996), empowerment is based on three coinciding dimensions such as knowledge, construction and capacity for more serious comprehension of social and political realities of one's environmental, development of a more positive and potent sense of self and development of strategies and resources or functional competences for achievement of collective and individual societal goals. The realization of these dimensions and the attainment subsequently, of being empowered are encouraged by the motivation domain, psychic comfort, solving problems and self-direction (Turner 1996). Conscious or unconscious action processes are part of motivation which is enhanced by the recognition of rewards or incentive. Built and sustained by the utilization and identification of internal characteristics of individuals like agreeableness, openness to experience, neuroticism, extraversion and conscientiousness and extrinsic factors, structural and social support, individual's hope is promoted by motivation to attaining his or her goals (Hart et al., 2007).

\subsection{Psychological Empowerment}

In spite of the rise in the empowerment interest as pointed out by Spreitzer (1995), the disappearance of psychological empowerment measures driven-theory in an environment will continue to prevent quality related resources in the work place

\section{Materials and Methods}

\subsection{Participants}

Our method of combined purpose sampling was adopted. Respondents were chosen using a criterion based technique whereas Snowball sampling was chosen to obtain data on the participants (Boyd 2001) which considered all the areas on how students/peoples have been empowered and what the perception of empowerment strategies in the place of study as well as show the level of students performances fully satisfied or fully unsatisfied. Boyd (2001) has demonstrated that 2 to 10 participants or research subjects are sufficient for most qualitative studies using similar approach. To identify the initial participants (Welman and Kruger 1999) was chosen. 
The criteria for choosing the study participants include: (a) respondents should be full tie postgraduate or undersgraduarte students; (b) they should have spent at least one and a half year at the university or later because it is assumed those who had more established relationship with the staff and other students with the staff and other students would be able to give more informed information; (c) they must come from diverse fields of study; (d) the overall sample should include those that have both positive and negative experiences with staff and other students on empowerment. The participants are drawn from faculties including Medicine, Engineering, Educational studies, and Science. A little more than half of the students that took part in the study are international students whereas the remaining comprised local Malaysian. Of the international students five were international $(n=5)$ students out of which two were Africans and two from Iranians while the other is from Myanmar while three are local Malaysians. Five of the respondents were males while three were females. The ages of the students range from 27 and 38 years. The respondents were observed and audio tape was used to record their responses and later their answers were transcribed. The first interview lasted for about 90 minutes, the second an hour, the third 45 minutes, while the rest lasted for 40 minutes.

The respondents were widespread in the Universities Putra Malaysia such as of health, education, Food Science and Technology, Human Ecology, Modern Language and Communication, Design and Architecture. This made it possible to interview a wider perspective of the students at different faculties at Universities Putra Malaysia.

Table 1. Number of informants by faculties and gender, martials status, qualifications, age's and countries

\begin{tabular}{|c|c|c|c|c|c|}
\hline No & Faculties & Gender's & StatusQualifications & Age's & Countries \\
\hline 1 & Faculty of Engineering & $\mathrm{M} /$ single & Undergraduate & 23 yrs. & India-Malay \\
\hline \multirow[t]{2}{*}{2} & Faculty of Educational Studies & M/ Married & Master & 30 yrs. & Nigeria \\
\hline & Faculty of Food Science and Technology & & & & \\
\hline 3 & & F/ Married & $\begin{array}{l}\text { Master } \\
\text { Students }\end{array}$ & 28 yrs. & Iranian \\
\hline & \multicolumn{2}{|c|}{4} & Master Students & 33 yrs. & Malaysia \\
\hline \multirow[t]{2}{*}{5} & Faculty of Modern Language and & & & & \\
\hline & $\begin{array}{c}\text { Communication } \\
\text { Faculty of Medicine and Health Science }\end{array}$ & M/Married & PhD students & $\begin{array}{l}38 \mathrm{yrs} \\
27 \mathrm{yrs}\end{array}$ & $\begin{array}{l}\text { Nigeria } \\
\text { Myanmar }\end{array}$ \\
\hline 6 & & F/ Single & Ms & & \\
\hline 7 & Faculty of Computer Science & $\mathrm{M} /$ single & Undergraduate & $21 \mathrm{yrs}$. & Iranian \\
\hline \multirow[t]{2}{*}{8} & Faculty of Design and Architecture & & & & \\
\hline & & F/ Married & $\mathrm{PhD}$ & 36 yrs. & Malaysia \\
\hline
\end{tabular}

This is purely qualitative research paper and it did not required statistical analysis but this demographic table is used to give a summary of the respondent's participants.

\subsection{Data Collection and Procedure}

Purposeful sampling (Creswell 2008) was used in agreement with the qualitative intention. Data was collected using indebt interview, semi-structured questionnaire and face to face interview. A guide to the interview consist a series of seven open-ended question which was designed to assist the students describe the nature of their experiences in their faculties. In-dept interview was added to ensure an acceptable level of dept knowledge from the respondents as well as provide an opportunity for information sharing or insights which students may be unwilling to disclose in a group setting. When students were approached to take part in the in-dept interview, majority showed the desire to provide information about their experiences. However, id no interest was shown in sharing their experiences, we did not include them in the study because we viewed this as an important criterion for taking part. A guide to the interview consisting of a series of open ended questions was adopted see the (appendix), this assisted the students to describe the nature of their relationship with their lecturers and other students.

\subsection{Data Analysis}

In this study, both within and phonological analyses were employed. The process of analysis was started right after the first interview was carried out and progressed until after the last interview was completed. The 
transcripts of the interview were analysed using content comparative method. Grounded theory guidelines were used for data analysis guide as reported by Chamaz (2005). The interview was analysed first based on personal level and then compared across subjects to identify patterns and common categories. Then the respondents view about empowerment were validated for context and meaning so as to articulate insight for each category. Paraphrasing Marshall \& Rossman (1999) have reported that the immersion assisted us for theme identification,pattern and category that came up to viewed the data obtained which were formed from the research questions. The interview transcripts were coded and used to generate and analyse themes including conclusions. The parterns that were used is open and initially examined to determine if individual's opinons could be joined into higher conceptual categories. As soon as the categories were built they were assessed for their dimensions of their views and comprehension (Rausch and Hamilton 2006). Glaser and Strauss (1967) have shown that via constant comparison analysis and were carried on the categories to explore their relationship to each other across the student interviews. After repeated reflection and inspection of our codes and categories, it's became clear that the concept of empowerment was sufficiently widen to become an overarching theme encompassing the preponderance of the statements used by the students

\section{Findings}

The findings are presented in response to the main research questions, "How do international graduate students experience empowerment at the Universiti Putra Malaysia and "How does their sense of empowerment influence their performance as students?" Three main themes and four sub-themes resulted from the analysis in relation to the nature of international student's perception of empowerment. Generally, the resulting themes illuminated the experience of students as one's empowerment strategies. Their experience with lecturer and phenomena could be understood according to five general categories: (a) accepting their task of study as students; and (b) coping with the environmental situation in order to improve and complete their study; (c) bridging the gaps for student's relationships at the university; and (d) high level of autonomy (e) the need for management policies to improve academic compatibility.Therefore, the author reported that the respondent's interviews as it is to support the findings because it was transcribed from audio tape.

According to one of the respondents, high degree of freedom makes students not to feel restricted in their studies area. Moreover, self-determination has to do with certain aims and objectives, an implication that the effort you put in, will assists in achieving one's set goals.

-The second respondent suggested that he feels empowered in the area of learning for example taking part in group assignment, social interactions among student, having access to the library and the internet. According to the respondents, the theoretical and practical methods of teaching assisted to improve learning; as well as studying in a conducive atmosphere enabled the informants cope with the academic calendar; by so doing feels empowered personally, psychologically and educationally.

The third respondent believed that there are loopholes in policy implementation at the university which are mainly due to language disparity. Much of the information is communicated in local languages which international students find difficult to understand. This has however, affected international student's' information sharing with the locals at the university.

The fourth respondent had suggested that there is no organization that hasn't got its problems; the problem envisaged university as lack of integration between the local and international students, discrimination, cultural differences also contributed to the loop holes. The management policy to recruit only local staff to manage the affairs of the university is a handicap to students improved performance. 


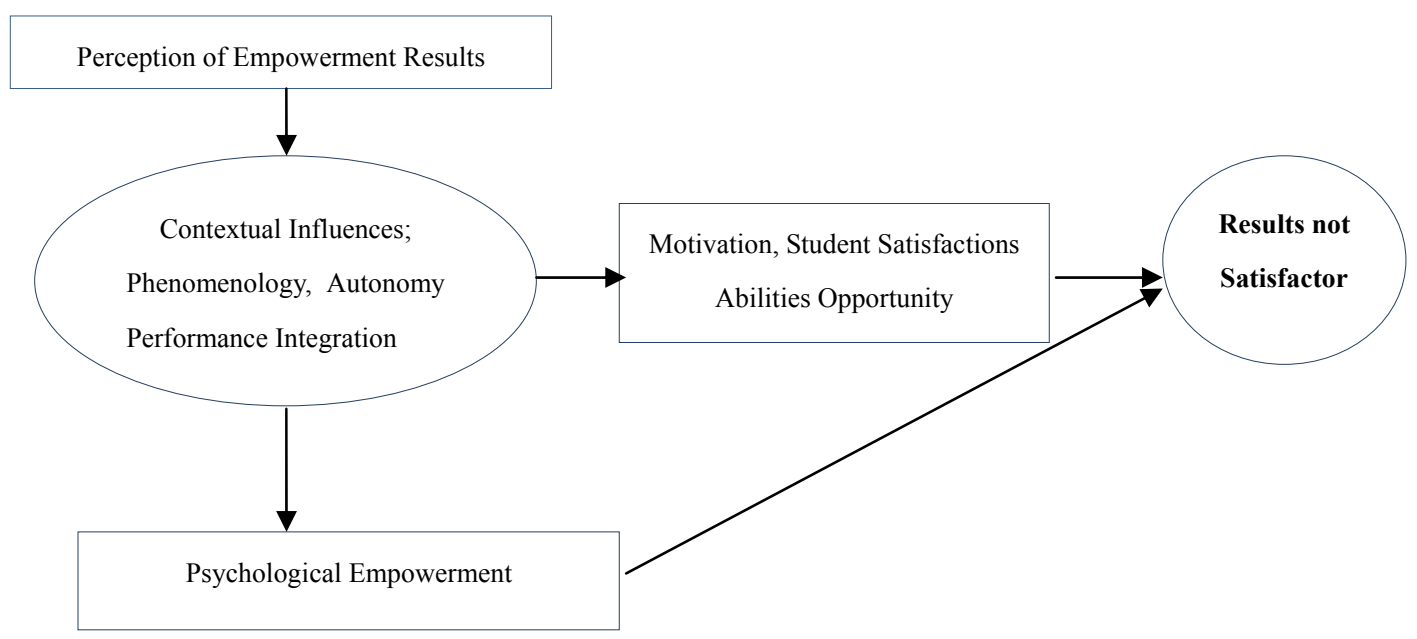

Figure 1. Diagram representation summary of the findings $\&$ results

\subsection{Results}

$\mathbf{P}=$ Phenomenology: There is very conducive environment.

$\mathbf{A}=$ Autonomy: There is high level of autonomy among student s.

$\mathbf{P}=$ Performance: Not satisfactory;

I = Integration: Not satisfactory;

\section{Discussion}

The present study examines many issues that are critically related to human resource management and development in the academic environment. It aims at exploring the experiences of student's empowerment, organizational support and performance outcomes at the Universiti Putra Malaysia. Klidas (2001) has shown that cultural factors are widely known to have a major influence on empowerment.Although staff, student empowerment and participation are popular management concepts in Western societies, and they are not freely adopted in some of the third world countries such as Malaysia. The university adoption of strategies aimed at empowering students encourages environmental knowledge-building and enhances positive individual growth of the student by the coordination and creation of reciprocal and positive association between students and staff Roger (1983). This kind of environment will recognize student's competencies, strengths, and resources accessible that will encourage motivation for desired goal achievement.

In addition, the empowerment of students in the university to encourage civility model will recognize the need to promote a social environment of self-esteem, self-efficacy, and lastly control the process of learning. Emphasizing on developing problem-solving skills, the model of empowerment for education improves critical thinking, adoption of reflective practice skills as well as the ability to affecting change.

As reported by one of the respondents, high degree of freedom makes students not to feel restricted in their studies area. Rinehart \& Short, (1994) have shown that autonomy refers to students' feeling that they have control over diverse areas of their study life, including curriculum development, scheduling, planning instruction and selection of textbooks. This control mechanism enables lecturers to feel free to make decisions in related to their educational environment. Empowerment of teachers has been reported in relation to student academic achievements (Marks \& Louis, 1997), participation in decision-making (White, 1992), and conflict and commitment (Wu \& Short, 1996; Johnson \& Short, 1998; Rinehart, Short \& Johnson, 1997).

In Malaysia, almost all of the information including notices is communicated in the local languages, which international students find difficult to understand. This has affected international students' information sharing with the locals at the University. Sometimes students may need to join some of the programs, exhibitions or classes, but because it is presented in the local language, may choose not to show interest as $\mathrm{s} /$ he may not understand what was communicated, it does not in anyway help to advance knowledge.

Moreover, management recruitment of local staff only, to manage the affairs of the university is not healthful enough to international students; it is a big handicap to students improved performance. Sometimes the lecturers show unfriendliness with international students, as some of them find it difficult to communicate with 
international students in English and as a result hinder progress at the university. This study however concluded that international students are experience some marginalization but were not disempowered at the university. This is due mainly to the fact that only local staff is the ones recruited in the workforce.

As a result indicated that the level of performance and integration were not satisfactory, it was recommended that management should assist in sensitizing local student's to feel free to socialize with international students for improved performance. Although some students feels some kind of motivation from some university lecturers and staff who show interest and concern on issues that concern their set goals. This however indicates that they are not in any way disempowered.

\section{References}

Bell, B. S., \& Kozlowski, S. W. J. (2002). A typology of virtual teams: implications for effective leadership. Group and Organization Management, 27, 14-49. http://dx.doi.org/10.1177/1059601102027001003

Bloom, S. L. (1998). Moral safety and responsibility in the evolution of a sane society. Paper presented at the United Nations meeting on the rights of the child, November 5, Nicosia, Cyprus.

Camp, S. L. (2003). Cultivating empowerment in nursing today for a strong tomorrow.

Charmaz, K. (2005). Grounded Theory in the 21st Century: Applications for Advancing Social Justice Studies. In Normann, K. D., \& Yvonna, S. L. (Eds.), The Sage Handbook of Qualitative Research (pp. 507-35). London: SAGE.

Clark, C. M. ( 2008). The dance of incivility in nursing education as described by nursing faculty and students.

Clark, C. M. (2009). Faculty field guide for promoting student civility.

Creswell, J. (2008). Educational Research: Planning, Conducting, and Evaluating Quantitative and Qualitative Research. New Jersey: Pearson.

Eisenberger, R., Stinglhamber, F., Vandenberghe, C., Sucharski, L., \& Rhoades, L. (2002). Perceived supervisor support: contributions to perceived organizational support and employee retention. Journal of Applied Psychology, 87, 565-573. http://dx.doi.org/10.1037/0021-9010.87.3.565

Glaser, B. G., \& Strauss, A. L. (1967). The discovery of grounded theory. New York: Aldine de Gruyter.

Han, S. S., Moon, S., Y., \& EunK, Y. (2009). Empowerment, job satisfaction, and organizational commitment: comparison ofpermanent and temporary nurses in Korea. Applied Nursing Research, 22(4), 15-20. http://dx.doi.org/10.1016/j.apnr.2009.06.004

Hart, J. W., Stasson, M. F., Mahoney, J. M., \& Story, P. (2007). The big five and achievement motivation: exploring the relationship between personality and a two-factor model of motivation. Individ Differ Res, 5, $267-74$.

Johnson, P. E., \& Short, P. M. (1998). Principal's leader power, teacher empowerment, teacher compliance and conflict. Educational Management and Administration, 26(2), 147-159. http://dx.doi.org/10.1177/0263211X98262004

Klidas, A. K. (2001). Employee empowerment in the European hotel industry: meaning, process and cultural relativity. Theta Thesis, Amsterdam.

Liden, R., Wayne, S., \& Sparrowe, R. (2000). An examination of the mediating role of psychological empowerment on the relations between thejob, interpersonal relationships, and work outcomes. Journal of Applied Psychology, 85(3), 407-16. http://dx.doi.org/10.1037/0021-9010.85.3.407

Malone, T. W. (1997). Is empowerment just a fad? Control, decision makingand IT. Sloan Management Review, $38,23-29$.

Marks, H. M., \& Louis, K. S. (1997). Does teacher empowerment affect the classroom? The implications of teacher empowerment for instructional practice and student academic-performance. Educational Evaluation and Policy Analysis, 19, 245-275.

Marshall, C., \& Rossman, G. B. (1999). Designing qualitative research (3rd ed.). Thousand Oaks, CA: Sage.

McQuillan, P. J. (2005). Possibilities and pitfalls: a comparative analysis of student empowerment. http://dx.doi.org/10.3102/00028312042004639

Moye, Meldina J., \& Henkin, A. B. (2005). Teacher-principal relationships: Exploring linkages Between Empowerment \& Interpersonal Trust. Journal of Educational Administration, 43(3), 260-277. 
http://dx.doi.org/10.1108/09578230510594796

Moye, M. J., \& Henkin, A. B. (2006). Exploring Association between Employee Empowerment \& Interpersonal Trust In Managers. Journal of Management Development, 25(2), 101-117. http://dx.doi.org/10.1108/02621710610645108

Nystanga, L., \& Dann, K. L. (2002). Empowerment in nursing: the role of philosophical and psychological factors. J. Adv. Nurs., 23, 305-13.

Parolia, N., Goodman, S., Li, Y., \& Jiang, J. J. (2007). Mediators between coordination and IS project performance. Information Management, 44, 635-645. http://dx.doi.org/10.1016/j.im.2007.06.003

Parson, R. J. (1991). Empowerment: Purpose and practice principles in socialwork. Soc Work Groups, 14, 7-21. http://dx.doi.org/10.1300/J009v14n02_02

Rausch, J. L., \& Hamilton, M. W. (2006). Goals and distractions: Explanations of earlyattrition from traditional university freshmen. The Qualitative Report, 11(2), 317-324. Retrieved June 5, 2008, from http://www.nova.edu/ssss/QR/QR11-2/rausch.pdf

Rhoades, L., Eisenberger, R., \& Armeli, S. (2001). Affective commitment to the organization: the contribution of perceived organizational support. Journal of Applied Psychology, 86, 825-836. http://dx.doi.org/10.1037/0021-9010.86.5.825

Rinehart, J. S., \& Short, P. M. (1994). Job satisfaction and empowerment among teacher leaders, reading recovery teachers, and regular classroom teachers. Education, 114(4), 570-580.

Rinehart, J. S., Short, P. M., \& Johnson, P. E. (1997). Empowerment and conflict at school-based and nonschool- based sites in the United States. Journal of International Studies in Educational Administration, $25,77-87$.

Sparks, B. A., Bradley, G. L., \& Callan, V. J. (199). An integrated model of customer satisfaction with service encounters involving failure and recovery. Journal of Marketing Research, 36, 356-372.

Sprietzer, G. M. (1995). Psychological Empowerment in The Workplace: Dimensions, Measurement, and Validation. Academy of Management Journal, 3(1), 1372-1445.

Turner, F. (1996). Social Work Treatment: Interlocking Theoretical Approaches (4th ed.). New York, NY: The Free Press.

Wall, T. D., Wood, S. J., \& Leach, D. J. (2004). Empowerment and performance. International Review of Industrial and Organizational Psychology, 19, 1-46.

White, P. A. (1992). Teacher empowerment under "ideal" school-site autonomy. Educational Evaluation and Policy Analysis, 14(1), 69-82.

Wu, V., \& Short, P. M. (1996). The relationship of empowerment to teacher job commitment and job satisfaction. Journal of Instructional Psychology, 25, 85-89.

\section{Appendix}

1. Interview questions

1) How do you understand the term, student's empowerment?

2) How do you experience empowerment in your faculty at the University.

3) Do you feel any form of motivation or satisfaction, and how?

4) How do you experience professional growth, and autonomy?

5) What are your perceptions about, self-determination, and competence and how does it relate to student performance?

6) Would you say that there are loop-holes as regards to empowerment policies and strategies of improving students' performances?

7) What are the roles of the lecturers, management and other students on the implementation of empowerment strategies. 


\section{Copyrights}

Copyright for this article is retained by the author(s), with first publication rights granted to the journal.

This is an open-access article distributed under the terms and conditions of the Creative Commons Attribution license (http://creativecommons.org/licenses/by/3.0/). 